\title{
A sexualidade humana no contexto da assistência de enfermagem
}

\author{
Nilza Tereza Rotter Pelá ${ }^{1}$ \\ Alexandra de Souza Melo ${ }^{2}$ \\ Waldirene Marta Salgueiro Santana ${ }^{2}$ \\ Antonio Lucas Nhamba ${ }^{2}$
}

\section{RESUMO}

Identificou-se entre 149 enfermeiros de Hospital Escola o quanto, em suas percepções, estavam eles instrumentalizados para assistir o cliente como "ser sexuado". Os dados obtidos evidenciam que os profissionais carecem de informação na área de sexualidade humana, dificultando sua vivência professional cotidiana, quando a questão do cuidado exige estarem instrumentalizados para lidar com a dimensão sexual de seu cliente. Concluem os autores que os profissionais não estão preparados

1 Prof. Dr. da Escola de Enfermagem de Ribeirão Preto-USP-Especialização Livre em Sexualidade Humana pelo Instituto H. Ellis-SP (1993).

2. Graduandos de Enfermagem ligados ao Programa de Iniciação Científica da EERP-USP. Recebido em 04.12.94

Aprovado em 08.01.95 
para cuidar do seu paciente como "ser sexual", e nem tem subsídios para refletir sobre sua própria sexualidade.

Unitermos: sexualidade humana, assistência de enfermagem.

\section{INTRODUÇÃO}

A literatura em Enfermagem tem enfatizado a importância do cliente ser atendido dentro de uma visão holística na qual a pessoa é percebida na sua individualidade, portanto o planejamento da assistência de Enfermagem deve pautar-se pelas singularidades desta individualidade $(1,3,5)$.

Em um olhar pela história da Enfermagem, podemos ver que, originariamente, a assistência aos pacientes era compreendida como um serviço a Deus embora em contraste, na fase anterior a Nightingale, fosse exercida na Inglaterra por prostitutas.

Com o advento da Enfermagem moderna, as regras de Florence Nightingale impunham um padrão de comportamento às enfermeiras, no qual a sexualidade era suprimida $(1,4)$.

HOGAN (1) e KRIZINOFSKI (2) apontam o fato de tradicionalmente a Enfermagem ter a permissão social de tocar qualquer parte do corpo do cliente para atender a exigência da manutenção da higiene a para prestar cuidados, mas pessoalmente quem assiste mantêm-se "puro" uma vez que o assistido é concebido como ser assexuado.

SOBRAL (6) lembra que, uma vez internado, o cliente "passa a ser percebido e tratado apenas como objeto da doença-cura e não mais como objeto do prazer".

Para MIRANDA (4) e SOBRAL (6) as enfermeiras ao ignorarem as necessidades sexuais de seu cliente tornam-se "purificadas" e desta forma têm "uma enorme dificuldade de interagir terapeuticamente com a sexualidade do outro e com a sua própria".

MC FARLONE \& RUBENFELD (3) recomendam que para a elaboração de um plano de assistência de enfermagem que envolva a integridade sexual do paciente é imperativo que o enfermeiro identifique suas limitações e capacidades para trabalhar nesta área. Esta avaliação envolve sua maneira de ser, conhecimentos, crenças, atitudes e valores.

Dentro desta ótica é necessário que a enfermeira determine o seu envolvimento no processo de aconselhar seus clientes na esfera da sua sexualidade. 
O modelo PLISSIT* proposto por Annon (apud RIEVE (5)) propõe 4 níveis de interação do profissional com o paciente no que diz respeito à sua sexualidade.

1 - Permissão

3 - Sugestões Específicas

\section{4 - Terapia intensa}

Neste nível de interação, o profissional é capaz de gerar um clima favorável para o paciente se expressar e discutir sobre suas preocupações sexuais.

2 - Informações limitadas Neste nível de interação o profissional é capaz de prover informações limitadas, tipicamente educacional e impessoal, relacionando a saúde sexual, em termos gerais.

Neste nível de interação o profissional tem conhecimentos específicos sobre sexualidade e disfunção sexual. Aqui, a história sexual deve ser obtida do cliente e do seu parceiro. O profissional deve ter domínio cognitivo sobre a sexualidade bem como, conhecer as patologias que interferem com a sexualidade do cliente. O profissional assiste o casal a estabelecer a alcançar metas específicas.

Neste nível de interação o profissional é capaz de auxiliar psicologicamente o paciente. Isto implica em domínio e habilidade de psicodinâmica, habilidade em assimilar e interagir com as respostas pessoais e da família.

Para RIEVE (5) todo enfermeiro deveria estar apto para atuar no nível 1 e deveria estar capacitado para intervir de maneira confortável e efetiva no nível 2. Preparação especial seria necessário para atuação nos níveis 3 e 4.

A literatura nacional tem escassez de publicações com dados referentes ao tema Sexualidade Humana no Contexto da Assistência de Enfermagem, assim o presente trabalho tem como objetivo identificar em enfermeiros de um Hospital Escola do interior paulista o quanto, na sua percepção, eles estão instrumentalizados para assistir o paciente como "ser sexuado".

\footnotetext{
* P-Permission

LI - Limited information

SS - Specific suggestion

IT -Intensive Therapy
} 


\section{METODOLOGIA}

A população em estudo constitui-se do total dos enfermeiros de um hospital escola do interior do estado de São Paulo que mantém uma unidade no Campus com aproximadamente 600 leitos, e uma unidade no centro da cidade com aproximadamente 250 leitos.

Desta população participaram do estudo todos os enfermeiros que estavam no exercício regular de suas funções sendo, portanto excluído os afastados para tratamento de saúde, os que estavam em gozo de férias assim a amostra foi composta de 169 enfermeiros.

A estes profissionais foe solicitado que respondessem um questionário auto-administrado com 17 itens que contemplavam as seguintes questões: identificação pessoal, informações sobre sexualidade obtidas durante o curso de graduação em enfermagem; vantagens destas informações a desvantagens acarretadas pelo conteúdo não ter sido ministrado; percepção da necessidade do conhecimento; qual disciplina ofereceu o conteúdo; assuntos abordados; vivência na prática que exigisse conhecimento na área; "distúrbios" sexuais que encontrou na prática; posição no "modelo PLISSIT" relativo ao seu preparo e sua percepção de qual deveria ser este preparo; interesse em cursos sobre Sexualidade Humana no Contexto da Assistência de Enfermagem; e comentários.

O questionário original foi submetido a uma validação aparente e de conteúdo, com a participação de 6 enfermeiros que participam de um grupo de estudo em Sexualidade Humana. Após as modificações propostas, foi realizado um estudo piloto com 10 enfermeiras, 5 da rede básica e 5 da unidade de internação que não pertenciam ao hospital em estudo, e o questionário foi avaliado como adequado para obter as informações que se pretendiam.

\section{RESULTADO}

Foram distribuídos 169 questionários sendo que 5 profissionais se recusaram a aceitá-lo e 15, embora tendo aceito, não o responderam. Além da clássica desculpa de falta de tempo para responder, outros argumentaram que, em sua pratica, não tinham possibilidade de vivenciar a questão da sexualidade humana, uma vez que trabalhavam em centro-cirúrgico e/ou central de material. Outro argumento usado para não responder foi que não saberiam como fazê-lo uma vez que no curso de graduação não tiveram informações específicas sobre o assunto. Argumentavam ainda que, embora os pesquisadores assegurassem sigilo, sentiam-se constrangidos em ter que "falar" sobre esta questão.

Assim a amostra em estudo passou a ser de 149 profissionais. As características desta amostra estão apresentadas no Quadro I. 
Quadro I - Características da amostra estudada.

\begin{tabular}{|c|c|c|c|c|}
\hline $\begin{array}{l}\text { CARACTERÍSTICA } \\
\text { MAIS FREQÜENTE }\end{array}$ & $\mathbf{F}$ & $\%$ & \multicolumn{2}{|r|}{ VARIABILIDADE } \\
\hline Sexo feminino & 137 & 91,95 & $(8,05 \%)$ & masculino \\
\hline Idade de 30 a 40 anos & 95 & 63,75 & 23 a 53 & anos \\
\hline Solteira & 79 & 53,02 & $\begin{array}{r}(42,28 \%) \\
(0,67 \%) \\
(0,67 \%) \\
(2,68 \%)\end{array}$ & $\begin{array}{l}\text { casada } \\
\text { viúva } \\
\text { desquitada } \\
\text { divorciada }\end{array}$ \\
\hline Católica & 108 & 72,48 & $\begin{array}{r}(14,09 \%) \\
(2,01 \%) \\
(0,67 \%) \\
(2,68 \%) \\
(0,67 \%) \\
(1,34 \%) \\
\end{array}$ & $\begin{array}{l}\text { espírita } \\
\text { cristã } \\
\text { budista } \\
\text { protestante } \\
\text { deísta } \\
\text { espiritualista }\end{array}$ \\
\hline Até 12 anos de formada & 87 & 58,39 & 1 a 32 & anos \\
\hline $\begin{array}{l}\text { Trabalho em unidade } \\
\text { médico cirúrgica }\end{array}$ & 83 & 55,70 & $\begin{array}{r}(10,07 \%) \\
(5,37 \%) \\
(6,04 \%) \\
(9,40 \%) \\
(6,04 \%) \\
(3,36 \%) \\
(2,68 \%) \\
(0,67 \%) \\
\end{array}$ & $\begin{array}{l}\text { pediátrica } \\
\text { psiquiátrica } \\
\text { neurológica } \\
\text { ambulatório } \\
\text { ginecológica e obstetrícia } \\
\text { berçário } \\
\text { moléstias infecciosas } \\
\text { dermatológica }\end{array}$ \\
\hline Enfermeira & 118 & 79,19 & $\begin{array}{r}(5,37 \%) \\
(12,08 \%)\end{array}$ & $\begin{array}{l}\text { diretora de serviço } \\
\text { enfermeira chefe }\end{array}$ \\
\hline
\end{tabular}

Os resultados acima apresentados evidenciam o perfil de uma população predominante feminina, como já era esperado. Predomina também na amostra a categoria enfermeira ou seja aquela que presta assistência direta aos pacientes, portanto com um repertório de vivência professional bastante rico o que sem dúvida lhes facultava contacto diuturno com a dimensão sexual de seus clientes.

Após os dados da identificação a primeira questão posta foi "ter tido conteúdo sobre sexualidade humana na sua formação acadêmica" responderam: não 86 (57,72\%); não lembro - 31 (20,81 \%); e sim - 32 (21,48\%). Dos que responderam sim, $19(59,37 \%)$ lembram-se em que período do curso tiveram esta informação que foi, em $10(52,63 \%)$ dos casos, ministrada no penúltimo ano de sua formação. Destacam-se as disciplinaas: Enfermagem Obstétrica, Psicologia, Enfermagem Psiquiátrica, Ética e Introdução à Enfermagem como sendo as mais citadas por terem ministrado o conteúdo.

Dos 32 enfermeiros que tiveram conteúdo de sexualidade na sua formação acadêmica, 28 (87,50\%) mencionaram 10 vantagens de ter recebido esta formação. O Quadro II apresenta a freqüência das 10 vantagens mencionadas pelos 28 sujeitos. 
Quadro II - Distribuição das 10 vantagens, por terem recebido conteúdo sobre sexualidade humana durante a graduação, mencionados por 28 enfermeiros.

\begin{tabular}{|l|c|}
\hline \multicolumn{1}{|c|}{ VANTAGENS } & F \\
\hline Favorece a interação paciente-enfermeiro & 17 \\
\hline Facilita a orientação de clientes & 14 \\
\hline Facilita a compreensão da vida pessoal e familiar & 7 \\
\hline Olhar a sexualidade como aspecto normal da vida & 5 \\
\hline Facilita a orientação da equipe de enfermagem & 3 \\
\hline Facilita identificar a necessidade do paciente & 2 \\
\hline Facilita avaliar o comportamento do paciente & 1 \\
\hline $\begin{array}{l}\text { Facilita o atendimento de pacientes com patologias envolvendo órgãos } \\
\text { genitais }\end{array}$ & 1 \\
\hline Quebra preconceitos & \\
\hline Facilita a prevenção de D.S.T. & \\
\hline
\end{tabular}

Pelas respostas evidencia o caráter facilitador do conhecimento sobre sexualidade humana no processo de relação interpessoal enfermeiro-paciente bem como destaca-se no Quadro II que a desinformação dificulta este mesmo relacionamento interpessoal. Assim dos 86 enfermeiros que não receberam qualquer informação sobre sexualidade humana na sua formação acadêmica, 68 (79,06\%) mencionaram 12 desvantagens deste evento. Um enfermeiro (sexo masculino) mencionou que não via qualquer desvantagem em não ter tido conteúdo específico sobre sexualidade humana na sua formação acadêmica.

O Quadro III apresenta as freqüências das 12 desvantagens mencionadas pelos 68 sujeitos. 
Quadro III - Distribuição das 12 desvantagens, por não terem recebido conteúdo sobre sexualidade humana durante a graduação, mencionadas por 68 enfermeiros.

\begin{tabular}{|l|c|}
\hline \multicolumn{1}{|c|}{ DESVANTAGENS } & F \\
\hline Dificuldade para conversar e/ou orientar cliente e família sobre o assunto & 40 \\
\hline Falta de conhecimento específico & 39 \\
\hline Inscgurança & 13 \\
\hline Constrangimento, falta de espontaneidade e inibição & 8 \\
\hline Dificuldade para esclarecer dúvidas próprias & 6 \\
\hline Dificuldade de atender às necessidades dos pacientes & 5 \\
\hline Não ver a sexualidade como aspecto normal & 3 \\
\hline $\begin{array}{l}\text { Não poder esclarecer a equipe de enfermagem como lidar com estas } \\
\text { questões }\end{array}$ & 2 \\
\hline Não estar atento para o assunto & 1 \\
\hline $\begin{array}{l}\text { Não saber como agir em "certas" situações } \\
\text { Dificuldade para que o paciente não confunda a atividade sexual com } \\
\text { libertinagem }\end{array}$ & 1 \\
\hline Timidez & 1 \\
\hline
\end{tabular}

Nos Quadros II e III onde predominam vantagens e desvantagens relativas à dimensão profissional sugerem a limitação dos entrevistados em se colocarem como pessoas que também necessitam de conhecimentos para sua compreensão como pessoas. Entretanto a maioria dos profissionais, $146(97,99 \%)$ declara ser necessário que se adquira conhecimentos sobre sexualidade humana durante a formação profissional. Destes profissionais, 125 (83,89\%) justificaram essa necessidade. Quadro IV apresenta estas justificativas. 
Quadro IV - Justificativa da necessidade de formação acadêmica na temática Sexualidade Humana.

\begin{tabular}{|l|c|}
\hline \multicolumn{1}{|c|}{ JUSTIFICATIVA } & F \\
\hline Conhecimento indispensável para o bom trabalho sem constrangimento & 55 \\
\hline Facilita esclarecer dúvidas, fazer orientações & 48 \\
\hline A sexualidade faz parte da natureza humana & 28 \\
\hline Compreensão da vida pessoal e familiar & 14 \\
\hline Identificar necessidade do paciente & 5 \\
\hline Na vida profissional temos freqüentes contatos com este assunto & 3 \\
\hline Necessidade de orientar equipe & 3 \\
\hline Area pouco abordada com o paciente & 2 \\
\hline Enfrentar melhor "certas situações" & 2 \\
\hline Porque é um assunto interessante e atual & 2 \\
\hline Facilita a entrevista com o paciente & 1 \\
\hline Dificuldade de lidar com grupos específicos & \\
\hline Total & \\
\hline
\end{tabular}

* Alguns sujeitos deram mais que uma resposta

Também aqui prevalecem os aspectos profissionais sobre os pessoais corroborando a já apontada dificuldade.

A reprodução humana, o desenvolvimento da personalidade, doenças sexualmente transmissíveis e desvios de comportamento sexual foram mencionados com maior frequiência como tendo sido os conteúdos ministrados durante a formação acadêmica. Muito pouco mencionados, aparecem o homossexualismo, a impotência, a frigidez, a fisiologia da resposta sexual, a masturbação, a sexualidade e hospitalização, a sexualidade de grupos específicos, e os abusos sexuais.

À questão "Você vivenciou alguma situação profissional que exigisse conhecimento sobre sexualidade humana", $91(61,07 \%)$ enfermeiros responderam sim; $52(34,89 \%)$ não; $1(0,67 \%)$ não se lembra; e 5 $(3,35 \%)$ não deram resposta.

Dos 91 enfermeiros que responderam sim, 69 (75,82\%) mencionaram 37 eventos que compreendiam situações e comportamentos conforme apresentado no Quadro V. 
Quadro V - Situações vivenciadas por 69 enfermeiros relativas à dimensão sexual de clientes.

\begin{tabular}{|l|c|}
\hline \multicolumn{1}{|c|}{ SITUAÇÕES } & F \\
\hline Esclarecimentos e orientação de paciente envolvendo questões sexuais & 39 \\
\hline Paciente psiquiátrico com distúrbio sexual & 9 \\
\hline Paciente referindo impotência & 8 \\
\hline Paciente se masturbando & 8 \\
\hline Atendimento de cliente homossexual & 7 \\
\hline Paciente internado referindo necessidade de satisfazer-se sexualmente & 5 \\
\hline Pacoente referomdp frigidez & 5 \\
\hline Paciente com priapismo & 4 \\
\hline No momento do procedimento de enfcrmagem paciente com ereção & 4 \\
\hline $\begin{array}{l}\text { No momento da tomada de sua história paciente colocando sua } \\
\text { dimensão sexual }\end{array}$ & 3 \\
\hline $\begin{array}{l}\text { Paciente ansioso pelo longo período de abstinência sexual decorrente da } \\
\text { internação }\end{array}$ & 3 \\
\hline Assistência de enfermagem a paciente com amputação de pênis & 3 \\
\hline Assistência de enfermagem a paciente que colocou prótese peniana & 3 \\
\hline Atendimento a criança vítima de estupro & 2 \\
\hline Paciente com alteração de imagem corporal & 2 \\
\hline Atração sexual de um paciente por um membro da equipe & 2 \\
\hline Atração sexual de um paciente por uma paciente & 20 \\
\hline Outros* & \\
\hline \hline
\end{tabular}

* Outros (com freqüência 1): Criança com crescimento de pêlos por uso de medicação; Surpreender um casal de pacientes tendo relações sexuais; Criança com má formaçäo genital; Paciente com curativo oclusivo por queimadura solicitando que alguém o masturbasse já que não podia fazê-lo; Paciente relatando relativamente extra-conjugal: Paciente falando a todo momento sobre sexo; Paciente que, na internação, manifesta-se preocupado com o periodo de abstinência sexual no hospital; Paciente recusando tratamento envolvendo órgãos genitais; Paciente com a libido aumentada: Paciente queixando-se de problemas conjugais; Cliente com sexualidade afetada pela doença do filho; Paciente com dificuldade de retorno à atividade sexual pós-cirurgia; Fazer parte do grupo clínico denominado "RN com sexo indeterminado"; Paciente fazendo gesto obsceno; Paciente que fugia do hospital para ter relaçoes sexuais: Constrangimento da paciente para submeter-se ao exame ginecológico: Revolta de um paciente submetido a quimioterapia quando soube que ficaria estéri]; Funcionário que abusou sexualmente de uma paciente: Tentativa de suicídio por carência afetiva: Paciente con trauma nos genitais.

Quando solicitados para mencionarem os comportamentos e situações vivenciadas onde o paciente apresentou "distúrbio sexual", 88 $(59,06 \%)$ sujeitos deixaram o item sem resposta e $61(40,93 \%)$ mencionaram 29 situações e/ou comportamentos que entendiam ser distúrbio conforme apresentado no Quadro VI. 
Quadro VI - Comportamentos e/ou situaçōes envolvendo pacientes e entendidos como distúrbio sexual pelos profissionais.

\begin{tabular}{|l|c|}
\hline \multicolumn{1}{|c|}{ SITUAÇÃO E/OU COMPORTAMENTO } & F \\
\hline Homossexualidade; bissexualidade; travestismo & 18 \\
\hline Inadequacidade sexual de pacientes psiquiátricos ou neurológicos & 8 \\
\hline Paciente se masturbando em público & 7 \\
\hline Paciente referindo impotência & 5 \\
\hline Paciente se masturbando em situação de privacidade & 4 \\
\hline Paciente com libido aumentada & 4 \\
\hline Paciente deprimido com impotência & 3 \\
\hline Exibicionismo & 3 \\
\hline Paciente falando a todo momento sobre sexo & 2 \\
\hline Paciente com priapismo & 2 \\
\hline $\begin{array}{l}\text { Esposa de paciente procurando ajuda para manter relações sexuais com } \\
\text { seu marido internado }\end{array}$ & 2 \\
\hline Paciente paraplégico e tetraplégico & 2 \\
\hline Paciente estuprada & \\
\hline Outros* & \\
\hline
\end{tabular}

* Outros (com freqüência 1): Paciente estimulando continuamente os órgãos genitais; Paciente que referia relações sexuais pela colostomia; Paciente que se dizia mulher grávida; Paciente com alteração de imagen corporal; Paciente com bexiga neurogênica; Paciente que chega ao hospital com tratuma de pênis; Páciente com rejeição pelo filho; Paciente homossexual masculino tentando manipular genital de profissional homem; Paciente ansioso pela abstin^encia sexual durante a internação: Paciente com amputação de pénis; Assistência a cliente com ficha policial de estrupador; Paciente com patologiu nos orgãos genitais; Paciente vebalizando fantasias eróticas.

Solicitou-se que os respondentes se situassem dentro do modelo PLISSIT quanto à percepção de seu preparo real e ideal para interagir com o cliente no que diz respeito à sexualidade. Os resultados acham-se apresentados no Quadro VII. 
Quadro VII - Percepções do profissional quanto ao seu preparo para interagir com o cliente com respeito a sexualidade deste, segundo o modelo "PLISSIT"

\begin{tabular}{|l|rr|rr|}
\hline $\begin{array}{l}\text { NÍVEIS DO } \\
\text { MODELO PLISSIT }\end{array}$ & $\begin{array}{c}\text { PREPARO } \\
\text { REAL }\end{array}$ & F \% & $\begin{array}{c}\text { PREPARO } \\
\text { IDEAL }\end{array}$ & \multicolumn{1}{|c|}{ F \% } \\
\hline Permissão & 43 & 28,85 & 11 & 7,38 \\
\hline Informações limitadas & 65 & 43,62 & 9 & 6,04 \\
\hline Sugestões especiificas & 12 & 8,05 & 46 & 30,87 \\
\hline Terapia intensiva & 2 & 1,34 & 63 & 42,28 \\
\hline Nenhum & 24 & 16,10 & 8 & 5,36 \\
\hline Sem resposta & 3 & 2,01 & 12 & 8,05 \\
\hline Total & 149 & 100,00 & 149 & 100,00 \\
\hline
\end{tabular}

Ao se colocarem em nível de preparo real 108 (72,46\%) dos sujeitos entrevistados consideram-se capazes de atuar e dar pelo menos algumas informações básicas sobre sexualidade humana e seus clientes. Preocupa-nos esta posição uma vez que ficou evidenciado que durante a graduação pouca informação sobre sexualidade humana é oferecido aos estudantes.

Quanto a uma futura participação em cursos que versarem sobre a temática sexualidade, $132(88,58 \%)$ profissionais manifestaram interesse; $9(6,04 \%)$ não se interessaram e $8(5,37 \%)$ não responderam.

Dos 149 respondentes $71(47,65 \%)$ acrescentaram comentários no final do questionário conforme apresentado no Quadro VII. 
Quadro VIII - Comentários feitos por 71 respondentes

\begin{tabular}{|c|c|}
\hline COMENTÁRIOS & $\mathbf{F}$ \\
\hline O profissional necessita de preparo nesta área & 31 \\
\hline Assunto importante, mas pouco trabalhado no dia a dia & 14 \\
\hline Espero por um curso & 12 \\
\hline Há necessidade de diminuir os tabus e preconceitos & 7 \\
\hline Assunto que mexe com todos e incomoda a maioria & 5 \\
\hline Todos têm curiosidade & 5 \\
\hline $\begin{array}{l}\text { Necessidade de un curso que além de teoria dê subsidios para atuação } \\
\text { profissional }\end{array}$ & 5 \\
\hline Quero saber o resultado desta investigação & 4 \\
\hline $\begin{array}{l}\text { Seria importante trabalhar com esta questão, entretanto há deficiência } \\
\text { numérica de pessoal para se preocupar com este assunto }\end{array}$ & 4 \\
\hline Minha área de atuação não levou-me a conviver com o assunto & 3 \\
\hline Procurei ser auto-didata no assunto & 3 \\
\hline Outros* & 13 \\
\hline
\end{tabular}

* Outros (com freqüência 1) Necessidade de melhorar o nível de educaçĩo sexaul no país; este é um assunto que deve ser tratado extensivamente para classes baixas; preocupo-me com o retorno à atividade sexual pós-cirúrgica dos pacientes; não me interessou o assunto; acho dfícil trabalhar com homossexual; profissional tem pouca oportunidade de freqüentar curso; tive oportunidade de conversar com pacientes que apresentavam impoténcia e compareceram ao hospital para avaliação; paciente interessado sexualmente pela enfermeira que deve ser desencorajado sem ofender; vivência junto a pacientes renais crônicos com impotência sexual; a realização de um curso sobre o tema me ajudará muito.

\section{CONSIDERAÇÕES FINAIS}

A recusa de respostas e a não devolução de questionários remetem para a percepção da temática em estudo como área difícil de ser trabalhada, percepção esta pela alta incidência de questões sem resposta ou com a resposta não lembro.

A maioria das vantagens mencionadas pelo fato de ter tido algum preparo durante a graduação, diz respeito à atividade profissional. Entretanto, pode-se constatar nas respostas dos enfermeiros a percepção de que ter algum conhecimento na área de sexualidade humana ajuda o indivíduo a visualizar a sua própria dimensão sexual (olhar a sexualidade como aspecto normal da vida; compreensão da vida pessoal e familiar). 
A desvantagem mais citada (dificuldade para conversar e/ou orientar o cliente a família sobre o assunto) sem dúvida é conseqüência da falta de conhecimento específico mencionado por 39 enfermeiros, o que também pode estar levando à insegurança mencionada por 13 profissionais.

Embora de forma tímida, aparece a referência de 6 enfermeiras das repercusões deste despreparo na sua própria vida sexual.

As justificativas da necessidade de formação acadêmica na temática de sexualidade humana evidenciam que o constrangimento frente a este aspecto do cliente é uma preocupação de aproxïmidade um terço dos profissionais estudados, mesmo que paradoxalmente destes um quarto assinale que a sexualidade "faz parte da natureza humana"; ou seja, é natural mas é constrangedor.

Será assim tãi constrangedor que 38,91\% dos profissionais estudados, negam, não respondem ou não se lembram de ter tido situações profissionais onde houve necessidade de relacionar-se com o cliente em sua dimensão sexual. Confirma-se aqui a argumentação de HOGAN (1), MIRANDA (4) e SOBRAL (6) que os enfermeiros ao ignorarem as necessidades sexuais de seus clientes tornam-se "purificados" e desta forma têm "uma enorme dificuldade de interagir terapêuticamente com a sexualidade dos outros e a sua própria".

Contudo, não tão negra é a situação visto que 69 (46,30\%) profissionais relatam 38 situações vivenciadas onde a dimensão sexual do paciente foi pelo menos identificada (Quadro V). A maioria dos profissionais mencionaram mais que uma situação, nos permitindo supor que quando a sexualidade do cliente não é negada pelo profissional ela é possível de ser identificada como todas as outras necessidades do ser humano.

Pretendia-se com a pergunta "teve a oportunidade de entrar em contati com algum paciente que apresentou distúrbio sexual? sim, não, se sim, qual distúrbio?", resgatar a percepção que os sujeitos têm de "distúrbio sexual". As respostas sugerem que assim é compreendido uma variedade de comportamentos ou situações que envolve desde desinteresse ou diminuição da libido, impedimentos físicos ou emocionais até exacerbação da sexualidade, desvio do padrão de expressão sexual socialmente aceito. $\mathrm{O}$ fato da grande maioria de respostas apontar o homossexualismo, bissexualismo e o travestismo como distúrbio sexual evidência o preconceito e a não aceitação da diversidade sexual como uma opção individual da pessoa.

Mesmo depois de terem declarado despreparo e dificuldade para assistir o cliente em sua dimensão sexual, 14 (9,39\%) enfermeiros se auto atribuiram aptidão para atuar nos níveis 3 e 4 do modelo PLISSIT. Mais preocupante ainda nos parece o fato de que $109(73,15 \%)$ enfermeiros tenham considerado que o preparo ideal para atender o cliente deva alcançar os níveis 3 e 4 do referido modelo. Isto se deve pura e simplesmente à ingenuidade decorrente do desconhecimento acerca do assunto ou à 
ingenuidade da onipotência que permeia a noção de que devemos, enquanto enfermeiros, ser "bons" em tudo o que fazemos.

Concluindo, podemos considerar que os profissionais não só carecem de informação como aspiram por preparo na área de sexualidade humana. O despreparo, evidenciado nas respostas ao questionário tem dificultado sua vivência profissional cotidiana quando a questão do cuidado exige estarem eles instrumentalizados para lidar com a dimensão sexual de seu cliente. Assim o cliente estaria sendo (des)assistido, ou seja assistido de forma a ignorar sua dimensão sexual. Por outro lado, este despreparo anula a capacidade do profissional para refletir sobre sua própria sexualidade.

\section{ABSTRACT \\ Human sexuality in the context of nursing care}

The study identified among 149 nurses of an university's hospital how much in their perceptions, they were instructed to assist the client as a "sexual being". The data showed that the nurses have information deficiency in human sexuality area, what difficults their professional daily experience when nursing care delivery requisit that they are skilled in order to provide care to the sexual dimension of their clients. The authors concluded that the professionals are not prepared to take care of their clients as a "sexual being" and neither have bases to reflect about their own sexuality.

Uniterms: human sexuality, nursing care.

\section{RESUMEN}

\section{La sexualidad humana en el contexto de la asistencia de enfermeria}

Se ha identificado entre 149 enfermeros de Hospital Escuela, cuanto, en sus percepciones, ellos estaban preparados para asistir el cliente como "Ser sexuado". Los datos obtenidos evidencian que los professionales carecen de información en el área de la sexualidad humana, dificultando su vivencia professional cotidiana, cuando la cuestión del cuidado, exige estaren preparados para lidiar con la dimensión sexual de su cliente. 
Concluen los autores, que los professionales no estan preparados para cuidar de su paciente como "ser sexual", y tampoco, tienen subsidios para reflectar sobre su propria sexualidad.

Unitermos: sexualidad humana, asistencia de enfermeria.

\section{REFERÊNCIAS BIBLIOGRÁFICAS}

1. HOGAN, R.: Human sexuality-A nursing perspective, $2^{\mathrm{a}}$ ed. Appleton, Century, Crofts. Connecticut, 1991.

2. KRIZINOFSKI, M. T.: Human sexuality and nursing practice enfermeira - The Nursing Clinics of North America, vol. 3, n 4, dec. 1973.

3. MC FARLANE, E. A.; RUBENFELD, M. G.: The need for sexual integrity. YURA, H. \& WALSH, M. B.: Human needs 3 and the nursing process, Appleton, Century, Crofts. Connecticut, 1983, pág. 185 a 233.

4. MIRANDA, C. M. L.; SOBRAL, V. R. S.: Sexualidade e enfermagem. Revista Brasileira de Sexualidade Humana, v. 3, ${ }^{\circ}$ 1, pp. 27-34, janeiro a junho de 1992.

5. RIEVE, J. E.: Sexuality and the adult with acquired physical disability. Nursing Clinics of North America, vol. 24, $\mathrm{n}^{\circ}$ 1, pp. 265-276, 1989.

6. SOBRAL, V. R. S. et al: A navegação da sexualidade nas práticas assistenciais de enfermagem. Cadernos de Enfermagem, v. 2, 2-6, 1989. 